\title{
a espetacularização do grotesco no cinema de almodóvar
}

\author{
Gabriela Borges
}

Pós-graduanda na Pl'C-SP

\begin{abstract}
This study aims to discuss three specific moments of three films by Spanish Director Pedro Almodovar: Matador (1986), Tacones Ltjauos (1990) cKika (1994).
\end{abstract}

KEY WORDS: Cinematographic Narrative - Dramatic Constmction - Grotesque.

Este trabalho pretende enfocar três momentos específicos de três filmes do cineasta espanhol Pedro Almodóvar: Matador (1986), Tacones Lejanos (1990) e Kika (1994).

Para facilitar a análise, os enredos serão relatados rapidamente, enfatizando o papel articulador da TV na narrativa cinematográfica. Sua presença constante, como uma espécie de personagem, levou a considerar a existência de um diálogo entre os três filmes.

$\mathrm{Na}$ tentativa de interpretar a ação dos personagens Angel, Rebeca c Andréa Caracortada, percebe-se que existem relações entre uma atuação espetacularizadora e reveladora e a intermediação promovida pela TV. A espetacularização e a revelação, por sua vez, caracterizam-se por apresentar algumas características como o grotesco e o ridículo, que serão aqui abordadas. 


\section{Gabriela Borges}

\section{Matador}

Dicgo Montes e Maria Cardenal têm o impulso incontrolável de matar seus parceiros sexuais. Uma busca frenética de uni transbordamento, uni rito de passagem na zona fluida e intermediària da morte. Angel. o anjo revelador da morte, tem vertigens que produzem uma realidade subjacente às imagens e à própria narrativa. Suas visões vêm fragmentadas, tentando ordenar e encaixar as pedras de uma espécie de quebra-cabeça. São os momentos de revelação da morte, que indicam o que aconteceu, está acontecendo ou vai acontecer.

O sentimento de culpa gerado pela tentativa de estupro de Eva noiva de Diego - faz com que Angel "confesse" a autoria de quatro assassinatos revelados em suas vertigens.

\section{A Espada e o Alfinete}

Numa aula sobre a arte de matar, Diego explica aos seus alunos como colocar-se diante de um touro bravo: o toureiro que toureia bem tem que matar bem, senão é uma desgraça tanto para ele, que não honra seu nome de matador, como para o touro, que trai sua braveza c coragem. Sua capa vermelha, que excita o animal, deve ser colocada perto do focinho para atraí-lo. A mão deve estar na altura do coração, para fazer o sinal da cruz e, sem afastar os olhos, cravar a espada: pois toureiro que não faz isso é levado pelo diabo. A estocada deve ser dada onde se juntam as paletas, na cavidade chamada "olho das agulhas" A espada deve ser bem-dirigida, para atingir o coração c pulmões, pois um touro bravo tem que ser morto como ele merece, não só com a espada, mas com o coração.

$\mathrm{Na}$ tela ocorre uma assíncrona entre som e imagem. Maria doma o toureiro e enfia o alfinete na sua nuca durante a relação sexual; matando-o e se excitando com esse gesto enquanto a voz de Diego em off fala sobre as formas de atacar o touro. Ao som dessa voz Angel vê, através da vertigem, Maria matando sua vítima dura.ite o ato sexual. $\mathrm{O}$ alfinete que ela usa vem fazer o contraponto da morte do homem e do touro. 
Dc um lado. Diego disputa com o touro um jogo agonístico. E de outro. Maria seduz o toureiro e o atrai para si. 0 alfinete e a espada são os instrumentos que penetram e matam, permitindo que sexo e morte se associem.

Entre eles se encontra Angel. que através de suas (telc)visões presencia esta associação. Mesmo confessando os assassinatos, ele não poderia ser o Matador, é o anjo que permite a revelação das mortes praticadas pelos serial killers Diego e Maria.

\section{A TV e as Vertigens Reveladoras}

Nos créditos iniciais Diego se masturba ao assistir na TV cenas de morte. Angel tem visões confusas dessas cenas com outras do próprio Diego matando suas alunas; o que lhe revela as mortes e permite que conte ao delegado de polícia como foram os assassinatos. Afirma ter matado dois homens, que tentaram manter relações sexuais com ele, e duas mulheres, uma estrangulada no estrado durante o ato sexual e outra afogada numa banheira.

Numa combinação de sons e imagens, a TV é a intermediadora. Angel confessa assassinatos que viu tanto na TV como em suas vertigens. A TV funciona como um estado alterado de consciência, como a vertigem, em que ficção e realidade se confundem. Angel passa a ser a metáfora da TV, pois tanto um como outro são veículos que permitem as revelações. Angel afirma ter matado uma mulher estrangulada da mesma maneira que Diego assiste, numa edição de imagens de filmes clássicos. a esse estrangulamento na cena justaposta ao título do filme: Matador. Esse é um eixo narrativo fundamental, pois a cena da TV passa para o enredo do filme como "reaf" como acontecimento. Foi entrevista em (tele)visões confusas e alucinadas nas vertigens e revelada pela confissão de Angel.

Ainda uma outra ação importante do filme ocorre através da TV. A revelação da tentativa de estupro de Eva por Angel, que é assistida por ela e por Diego no telejornal noturno. Diego ensina a seu aluno que a 


\section{Gabriela Borges}

mulher tem que ser encarada e encurralada sem que perceba, assim como o touro. E o que Angel pretende, mas não consegue realizar.

\section{Ta cones Lejanos}

Ao longe Rebeca ouve o som dos saltos da cantora pop Becky, sua mãe. Ela chega a Madri depois de uma estada de 15 anos no México. Num flash-back Rebeca se recorda da morte de Alberto, marido de sua mãe. Ainda menina, assiste pela TV à notícia do acidente de carro ocorrido pelo fato de Alberto ter dormido ao volante. Rebeca havia trocado as pílulas estimulantes por tranqüilizantes.

Agora casada com o diretor do canal de TV Tele 7, Rebeca havia se tornado apresentadora do telejornal noturno.

Paralelamente a isso Rebeca conhece Femme Fatale, um travesti que faz shows pop no submundo madrileno e que é sósia de Becky. Ele se veste como ela. canta como ela e é apaixonado por sua filha.

Um mês depois da chegada de Becky, dom Manuel Sancho, marido de Rebeca, é encontrado assassinado em seu chalé. O juiz encarregado do caso. que não é ninguém mais do que Fatale interpretando outro personagem, entrevista suas três mulheres: Rebeca, Becky e Isabel, a apresentadora de surdos-mudos no telejornal de Rebeca.

Nenhuma delas confessa o assassinato. Até que Rebeca, na apresentação do telejornal exatamente no dia do enterro, conta, ao vivo. exatamente como o assassinou. No mesmo dia em que Rebeca é presa. Beckv estréia seu show em Madri. Na prisão, ela assiste pela TV sua mãe dedicar-lhe a música Pense em mi, leitmotiv do filme.

Ao ser solta, pois o juiz/Fatale não encontrou provas que a incriminassem, Rebeca corre até sua casa, a qual havia sido revirada pela polícia, e encontra a arma do crime exatamente no lugar em que havia escondido, ou seja, dentro da TV. 
Em Tacones Lejanos a TV funciona como reveladora tanto ao transmitir a morte de Alberto como a confissão do assassinato de dom Manuel por Rebeca. Mas também exerce o papel de cúmplice, ao atuar como lugar de ofuscamento, pois serve de esconderijo para a arma do crime. A polícia não levantou nenhuma suspeita de que poderia estar ali, justamente dentro da TV, o revólver que matou dom Manuel.

Rebeca, como Diego e Maria de Matador, é uma serial killer. Ela mata o primeiro marido da mãe, depois se casa com o ex-amante dela e o mata também. Os assassinatos estão ligados ao sexo. Rebeca, ao se desfazer dos amantes da mãe, queria seu amor e atenção. O que só conseguiu quando ela estava no leito de morte e confessou ao juiz que havia matado dom Manuel. Fez isso para que Rebeca ficasse livre e pudesse criar a criança, filha de Fatale, que carregava no ventre.

\section{Kika}

Ramón, o fotógrafo de moda e namorado de Kika, é um voyeur. Com um prazer escondido, seu olhar se deleita espiando Kika. Numa tarde presencia o estupro de sua mulher pelo ex-ator pornô Paul Bazzo, que é irmão de sua empregada Juana e tinha acabado de fugir da prisão. Ao procurar pela irmã, encontra Kika dormindo tranqüilamente. Como não consegue resistir, pratica o estupro mais demorado da história do cinema. São doze minutos que misturam tensão, descontração, raiva, bate-papo e indignação de Kika, que tenta a todo custo convencê-lo de sair de cima dela, pois o ator quer bater seu recorde de quatro ejaculações sucessivas.

A atitude voyeurista não se restringe ao fotógrafo. Andréa Caracortada, ex-namorada de Ramón e apresentadora do programa de TV O Pior do Dia, também espia Kika e Nicolas. Ele é o padrasto de Ramón que chegou de uma viagem à América Latina e está hospedado no estúdio de Ramón, situado no andar acima do apartamento do casal.

Não se sabe como, mas Andréa conseguiu filmar as cenas do estupro de Kika e foi procurá-la para obter uma entrevista, a qual foi 


\section{Gabriela Borges}

recusada. Com sua câmera ligada ininterruptamente, Andréa personifica o voyeurismo da TV, que fica à espreita, esperando um "fủro" de reportagem. O curioso é que, mesmo invadindo a privacidade de Kika, seu discurso é de que ela estava atentando contra a liberdade de expressão ao recusar a entrevista. A TV e conseqüentemente os telespectadores, na visão de Andréa, têm o direito de saber o que se passou com Kika. Sua vida virou notícia e automaticamente um produto que aumenta os índices de audiência e estimula a venda do leite $A$ Real.

O Pior do Dia espetaculariza a notícia, exibindo-a em forma de show. Esse gênero de telejomalismo possui uma câmera cândida, espiã e bisbilhoteira. Suas investigações se confündem com a própria investigação policial, cumprindo a proposta do inglês Jeremy Bentham ${ }^{1}$ de uma sociedade autovigiada.

São essas notícias espetaculares que Andréa traz para o seu reality show, com imagens furtadas na cidade e entrevistas ao vivo de vítimas ou parentes de vítimas de escândalos.

Assim como Andréa espia Kika, também dirige seu olhar voyeur a Nicolás. Ele é um escritor de romances policiais que têm sempre como protagonista um serial killer, além de escrever roteiros para o programa televisivo de Andréa.

Como já estava desconfiada das histórias contadas nos romances de Nicolás, Andréa capta imagens com sua câmera através da janela do apartamento do escritor. Numa reconstituição frame a frame, descobre que ele matou uma loura mexicana usando um vaso de flores. Com a exibição do estupro de Kika na TV ele fica muito preocupado, pois precisa saber quais as imagens que Ramón possuía, e como Andréa havia conseguido as imagens do estupro.

\footnotetext{
1. Para Bentham os panópticos eletrônicos estarão de tal-modo presentes na vida cotidiana das pessoas que exercerão um poder de coerção imaginária. A sua força como agente repressor atua no sentido delas se sentirem permanentemente vigiadas, numa atmosfera de paranóia produzida artificialmente, que coíbe a ação transgressora antes mesmo que ela possa ser praticada.
} 
Andréa procura Nicolás para obter a confirmação de suas suspeitas, pois estava achando que aquelas histórias eram reais e não apenas ficção como ele afirmava. Atira na sua perna e pede que ele confesse ser o serial killer, antes de levá-lo ao hospital. Oferece dinheiro e a segurança de que a notícia só vai ao ar quando ele estiver bem longe. Numa cena patética, em que Andréa chora para conseguir o maior "furo" de reportagem de sua vida, os dois se matam no chão da casa Youkali.

Andréa mata Nicolás no desespero de conseguir as informações. Ela é a mídia, que devora avassaladoramente, que não permite nenhum deslize e absorve o máximo que consegue. E Nicolás mata Andréa, mata a mídia e sua força assustadora. Mata porque é um serial killer. Matou a mãe de Ramón, matou a loura mexicana e agora Andréa. Ele confessa a Kika, minutos antes de morrer, que aquele romance era sua autobiografia e que a lésbisca serial killer era ele mesmo. No entanto, impediu que Andréa descobrisse tal fato para transmitir no seu programa.

\section{TV: Espetáculo e Revelação}

A presença dos meios de comunicação de massa e especialmente da TV nos filmes de Almodóvar é uma constante. Observa-se que a TV exerce uma "espécie de invasão branca, invisível e indolor" (MACHADO, 1993: 93). Como um panóptico, ela atua nos filmes da mesma maneira que na sociedade contemporânea. Está onipresente, intermediando os acontecimentos e espetacularizando as revelações da vida das pessoas, principalmente àquelas que envolvem sexo e morte. Lembrando o que nos diz Machado, a TV é a

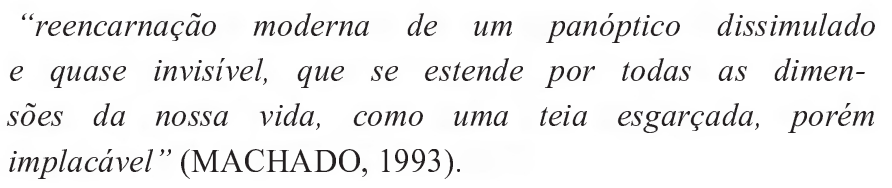

Considerando sua presença permanente na narrativa cinematográfica dos filmes Matador, Tacones Lejanos e Kika, a análise procura 


\section{Gabriela Borges}

estabelecer um diálogo entre eles com o intuito de perceber um traço comum ao estilo do cineasta.

Em Matador, Angel confessa os assassinatos praticados por Diego devido às suas (tele)visões confüsas e alucinadas das cenas de morte na TV. A ficção, fruto das vertigens de Angel e das imagens da TV, é inserida no relato a partir do momento em que ocorre a revelação das mortes.

Em Kika, a vida privada das personagens é objeto de espetáculo do programa de TV O Pior do Dia. Sua repórter, metáfora do caráter bisbilhoteiro e avassalador da mídia, é morta na tentativa de obter o maior furo de reportagem de sua vida.

Os meios de comunicação de massa promovem de tal modo a especulação da vida privada na esfera pública, encontrada no domínio da TV e da própria mídia, que hoje elas se encontram totalmente imbricadas e entrelaçadas. Michel FOUCAULT (1977:190) observa que nossa sociedade não é de espetáculos, mas de vigilância. Esse poder de vigilância está em transformar o próprio espetáculo em observatório de vigilância. Isto é obtido através dos meios de comunicação de massa e da espetacularização da vida privada de pessoas comuns. O espetáculo, que anteriormente era vivido apenas como manifestação cultural autêntica, é incorporado pela TV e adquire o estatuto de simulação ao se tomar imagem eletrônica.

Tanto em Matador como em Kika ocorre a espetacularização do estupro das personagens ao serem revelados pela TV. Em Matador, a modelo Eva assiste com seu noivo, Diego, à notícia de que foi estuprada por Angel. Em Kika, ela e seu namorado, Ramón, assistem às cenas de seu estupro no programa televisivo de Andréa Caracortada.

Além da espetacularização, os filmes tratam da revelação da morte, característica presente também em Blow-up (1966). Em seu filme, Michelângelo Antonioni nos conta a história de um fotógrafo que andava pelas ruas de Londres com sua câmera e acabou captando 
algumas imagens de um casal no parque. A mulher, ao ser fotografada, ficou apavorada e procurou o fotógrafo para pedir-lhe os negativos. Numa reconstituição de imagens na ampliação das fotos, ele descobre que presenciou e, mais que isso, registrou um assassinato. 0 dilema do personagem se faz na dúvida de denunciar ou não tal fato, pois se ficasse calado provavelmente ninguém saberia do ocorrido.

Os personagens de Almodóvar descobrem e, quando possível, denunciam os assassinatos. Em Kika, Andréa Caracortada estava sedenta de informações inusitadas para aumentar os índices de audiência de seu programa; só não denunciou Nicolas porque foi morta antes que ele se confessasse. Em Matador, as mortes presentes nas imagens de TV só participam do relato porque Angel as captura nas vertigens e as insere no universo do filme ao confessar ser o assassino.

Em Tacones Lejanos, as duas instâncias, a espetacularização e a revelação, estão presentes. A TV não só espetaculariza a morte de Alberto, ao revelá-la no telejomal noturno, mas também atua como veículo de transmissão direta da confissão de Rebeca, a qual, se tivesse ficado calada, provavelmente ninguém saberia que era a assassina. A personagem é o meio pelo qual o fato imagético real é inserido no enredo do filme, por intermédio de um outro meio, virtual, a TV.

Ao privilegiar a experiência viva, in corpore, a TV toma verossímel tudo o que acontece. A tal ponto de inverter

\section{" a condição de observador a observado e de espectador a espetáculo, devido a reversibilidade das tecnologias de registro e exibição" (MACHADO, 1993: 99).}

Por outro lado, o voyeurismo coletivo do público se deleita com a emissão direta, ao vivo e em cores onde o telespectador é colocado no interior da imagem e do próprio acontecimento. Sem dúvida que o telespectador se sentiu participante do desvendamento da trama em torno do assassinato de dom Manuel ao assistir à confissão ao vivo de Rebeca. 
A TV, ao atuar como reveladora das mortes nos diferentes enredos, acaba promovendo uma inversão de seu próprio caráter mediático, de estar entre o homem e o mundo como imagem, virtual por definição. Nesse caso, a imagem, apesar de ser virtual, permite a revelação de uma realidade verossímel para o plano ficcional das narrativas fílmicas.

BAUDRILLARD (1993:147) coloca que o cinema ainda permite, atrás da imagem, a transcendência do imaginário, pois encena a ficção como realidade, misturando essas duas instâncias de forma projetiva. Entretanto, a televisão, que pretende encenar a realidade como realidade, abole toda essa distinção e permite apenas uma percepção-tela, onde a imagem só remete a si própria. A imagem-foto e a imagem-cinema passam pelo processo do negativo, enquanto a imagem-televisão e a imagem-vídeo são imagens sem negativo. São virtuais e sem negatividade, logo, sem qualquer referência à história ou ao acontecimento.

Essa proliferação de imagens permite que a TV produza a informação como espetáculo,

"não pretendendo representar o mundo, mas a si mes-

ma, às suas próprias formas e linguagens, num cons-

tante presente performático" (CONNOR, 1993: 139).

Paradoxalmente, a ocorrência do discurso espetacularizado e autoreferente da televisão na narrativa cinematográfica almodovariana promove não só a encenação da ficção como realidade, mas da própria ficção como ficção, que se toma realidade ao ser colocada como imagem-cinema.

\section{O Grotesco e o Ridículo}

Os personagens Angel, Rebeca e Andréa Caracortadâ atuam como a metáfora da TV e de sua performance no mundo contemporâneo. Em Cultura Pós-Moderna, Connor coloca que a tela da TV é a 
metáfora da visibilidade absoluta, onde o privado é colocado na ordem do público a tal ponto de ser chamado de obscenidade:

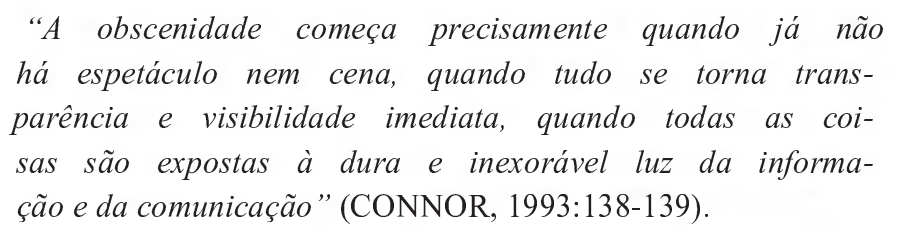

Nos respectivos filmes que protagonizam, as personagens tornam-se uma tela pura, para onde convergem o espetáculo e a revelação. Essa realidade intermediada pela TV, vertiginosa e obscena, permite que alguns fatos, geralmente não-apresentáveis, como a confissão de Rebeca ou os estupros da modelo Eva e da maquiadora Kika ou mesmo a morte patética de Andréa, sejam banalizados e transmitidos como lugar-comum. Essas transmissões acabam por derrubar as barreiras que mantém o profano longe do cotidiano.

Mesmo sabendo que a ficção consegue fazer uso de situações estranhas sem causar o mesmo estranhamento que ocorreria no âmbito da vida real, a "estranheza" provocada por essas transmissões, justamente por serem fatos cotidianos pertencentes à vida privada, caracteriza-se por colocá-las perto do caricatural e do grotesco.

Para SODRÉ (1988:73) o grotesco é apresentado como signo do excepcional, é visto como signo do outro. Sua intenção é sempre colocar-se diante de algo que está entre nós, mas que ao mesmo tempo é exótico, logo sensacional.

Em outros termos, o grotesco é uma aberração, que na esfera da cultura de massa, em face da sofisticação da sociedade de consumo, é visto como tal especialmente quando apresentado como espetáculo.

O grotesco espetacularizado ridiculariza a situação dos personagens nas transmissões televisivas. Ele pode ser percebido no ridículo da situação de personagens como Andréa Caracortada - com um figurino 
high-tech e uma camêra de vídeo presa na cabeça, ela captura imagens para exibir no seu programa: como a cena ridícula de Kika ao tentar fazer com que Paul Bazzo pare de estuprá-la. Ela acaba sendo assassinada pateticamente, ao chorar para conseguir a confissão de Nicolas -; na ridícula confissão de Rebeca, que se toma espetáculo do telejomal que apresentava; e também na tentativa de estupro de Eva empreendida por Angel, que, mesmo sem conseguir a efetivação de tal ato, toma-se notícia espetacularizada e vítima da ridicularização promovida pela TV.

Angel, diferentemente de Rebeca e Andréa, é a metáfora da TV porque, como ela, é o veículo de revelação. Rebeca, ao se confessar, toma-se veículo de sua própria espetacularização; Andréa promove a espetacularização de outras pessoas. Angel não espetaculariza, ao contrário, é vítima da espetacularização.

Em Matador, o grotesco, mesmo espetacularizado, adquire um caráter escatológico. As cenas de morte, presenciadas nas visões por Angel, tanto por estrangulamento como por afogamento na banheira, são aberrações que causam repulsa e estranhamento.

Os personagens caricatos, enquanto aberrações, também são espetacularizados, como Kika, com seus figurinos kitsch, abusando do vermelho e do laranja; o travesti Femme Fatale, com sua performance pop; e mesmo Andréa, que não deixa de ser a caricatura do aparato técnico da mídia na contemporaneidade.

O humor negro, amargo, às vezes cruel dessas cenas têm um ar pirandelliano ${ }^{2}$, pois mesmo provocando o riso e exibindo sua face cômica, traz em si a tragicidade da existência. Usa a inteligência para se distanciar e certas doses de amargura para falar daquilo que não está explícito.

2. O autor italiano PIRANDELLO (1993), em seu livro L'Umorismo, afirma que o humor, mesmo provocando o riso, aponta para o trágico da existência. 
Para Almodóvar, o humor se encontra numa linha tênue, ao longo da qual está o grotesco e o ridículo:

"En mis películas todo está al borde de la parodia. No

es sólo parodia, es también la línea límite de lo ridículo

y lo grotesco pero fácilmente se puede caer al otro lado

de la línea" (GARCÍA DE LEON e MALDONADO,

1989:167).

A relação existente entre o cinema almodovariano e urna característica grotesca e ridicula intermediada pela televisão leva a considerar a possibilidade de se pensar numa intertextualidade entre essas linguagens, que se imbrican! e projetam seu movimento. Percorrendo não somente a linha que permeia o grotesco e o ridículo, mas também aquela que se encontra entre o real e a ficção, entre o tangível e o intangível da imagem.

\section{Bibliografia}

BAUDRILLARD, Jean. (1993).Televisão/revolução: o caso Romênia. In: PARENTE, André (org.). Imagem-máquina. A era das tecnologias do virtual. Rio de Janeiro, Editora 34.

BERNARDET, Jean-Claude. (1994). A crueldade irônica. Revista Imagens, Campinas, Editora da Universidade de Campinas, n. 2. ago., p. 40-43.

BENTES, Ivana. (1994). Aqui Agora: o cinema do submundo ou o teleshow da realidade. Revista Imagens, Campinas, Editora da Universidade de Campinas, n. 2, ago., p. 44-49.

BOQUERINI, F.B. (1989). Pedro Almodóvar Madrid, Ediciones JC.

CALABRESE, Ornar. (1988). A idade neobarroca. Trad. de Carmen de Carvalho e Artur Mourão. São Paulo, Livraria Martins Fontes Editora Ltda.

CAPUZZO, Heitor. (1993). Alfred Hitchcock: o cinema em construção. Vitória, Fundação Ceciliano Abel de Almeida/UFES.

CONNOR, Steven. (1993). Cultura pós-moderna. Uma introdução às teorias do contemporâneo. São Paulo: Loyola. 
ECO, Umberto. (1985). Pós-escrito a O Nome da Rosa. Trad. de Letizia Zini Antunes e Aĺvaro Lorencini. Rio de Janeiro, Nova Fronteira S/A.

FOUCAULT, Michel. (1977). Vigiar e punir: nascimento da prisão. Trad. de Ligia M. Pondé Vassalo. Petrópolis, Vozes.

HUGO, Victor. (1988). Do grotesco e do sublime. Trad. Do Prefácio de Cromwell. Trad. e notas de Célia Berretini. São Paulo, Perspectiva S/A.

GARCÍA DE LEON, M. A. e MALDONADO, T. (1989). Pedro Almodóvar, la otra España cañi (sociologia e critica cinematográficas). 2. ed. Ciudad Real, Diputación de Ciudad Real. Area de Cultura.

MACHADO, Ariindo. (1993). Máquina e imaginário. São Paulo, EDUSP.

MARTIN, Marcel. (1971). A linguagem cinematográfica. Lisboa, Preio.

MENEZES, Philadelpho. (1994). A crise do passado - modernidade, vanguarda, metamodernidade. São Paulo, Experimento.

MORIN, Edgar. (1988). O homem e a morte. Portugal, Europa-América.

NOVAES, Adauto (org.). (1991). Rede imaginária. Televisão e democracia. São Paulo, Cia. das Letras.

(1993). O olhar. São Paulo, Cia. das Letras.

PARENTE, André (org.). (1993). Imagem-máquina. A era das tecnologias do virtual. Rio de Janeiro, Editora 34.

PIRANDELLO, Luigi. (1993). L'Umorismo. Roma, Tascabili Economici.

SANTAEllA, Lúcia. (1994). Estética de Platão a Peirce. São Paulo, Experimento.

VATTIMO, Gianni. (1991). A sociedade transparente. Trad. de Carlos Aboim de Brito. Lisboa, Edições 70.

VIRILIO, Paul. (1994). A máquina de visão. Trad. de Paulo Roberto Pires. Rio de Janeiro, José Olympio. 